\title{
Peptide and Protein Analysis by Electrospray Ionization- Mass Spectrometry and Capillary Electrophoresis-Mass Spectrometry
}

\author{
Joseph A. Loo, Harold R. Udseth, and Richard D. Smith ${ }^{1}$ \\ Chemical Methods and Separations Group, Chemical Sciences Department, Pacific Northwest Laboratory, \\ Richland, Washington 99352
}

Received January 24, 1989

The extension of mass spectrometry to high molecular weight biopolymers based upon electrospray ionization and the on-line combination with capillary electrophoresis is described. Electrospray ionization produces gas-phase intact multiply charged molecular ions of biomolecules from highly charged liquid droplets by a high electric field. For high molecular weight substances electrospray ionization results in a characteristic bell-shaped distribution of multiply charged ions, with each adjacent major peak in the spectrum differing by one charge. Multiply charged molecular ions of proteins with molecular weights greater than 130,000 have been observed with a quadrupole mass spectrometer of limited mass-to-charge range $(\mathrm{m} / \mathrm{z}$ 1700). Molecular weights can be readily determined for large proteins with accuracies in the range of \pm 0.01 to $0.05 \%$; at least an order of magnitude further improvement appears feasible with improved techniques and instrumentation. The electrospray ionization method is sensitive, presently requiring samples in the 100 fmol to 10 pmol range for proteins. Initial results combining rapid separations by capillary zone electrophoresis with online mass spectrometric detection via the electrospray ionization source are demonstrated for myoglobin and other proteins and polypeptides. The potential for extension of these methods to molecular weights on the order of $10^{6}$ is discussed. 1989 Academic Press, Inc.

Mass spectrometry (MS) is probably the most broadly applicable analytical tool in the chemical sciences and is becoming increasingly important in biological research as capabilities to address large molecules advance. The molecular weight range amenable to MS has increased

\footnotetext{
${ }^{1}$ To whom correspondence should be add. essed.
}

at an explosive rate in the past decade. Before 1980 it was difficult to analyze nonvolatile biomolecules with molecular weights in excess of 1000 by MS. Desorptionionization techniques such as fast atom bombardment (1) and californium-252 plasma desorption (PD) $)^{2}(2,3)$ extended the mass range in the early 1980 s, with singly and multiply charged molecular ions being observed by PD-MS for porcine pepsin $\left(M_{\mathrm{r}} \sim 33,633\right)(4,5)$. Multichannel array detectors on magnetic sector instruments together with irradiation by higher energy ions have improved detection sensitivities and allowed proteins as large as trypsinogen $\left(M_{\mathrm{r}} \sim 24,000\right)$ to be analyzed using liquid secondary ion MS (6). Laser desorption (266-nm photons) with the use of a special organic sample matrix has recently allowed ionization of a $170-\mathrm{kDa}$ protein $(7,8)$. Despite these successes, the further extension of mass spectrometry depends on the development of methods with improved sensitivity, broader applicability, the ability to obtain both accurate molecular weights and (ideally) structural information, and, perhaps most importantly, the on-line combination with microscale separation methods.

Electrospray ionization (ESI), pioneered by Dole et al. (9), and recently rejuvenated by Fenn and co-workers $(10,11)$, is a "soft" ionization method capable of producing multiply charged molecular ions. ESI involves an electrically induced nebulization process producing highly charged droplets in a dry nitrogen atmosphere that causes the droplets to shrink to their charge limit, resulting in ion desorption or evaporation of intact molecular ions. Dole and co-workers reported tentative indications that small proteins such as lysozyme $\left(M_{\mathrm{r}}\right.$ $\sim 14,300$ ) and organic polymers as large as $800,000 \mathrm{Da}$

\footnotetext{
${ }^{2}$ Abbreviations used: PD, plasma desorption; ESI, electronspray ionization; CZE, capillary zone electrophoresis; CID, collision-induced dissociation; FWHH, full width at half the peak height.
}

0003-2697/89 $\$ 3.00$ Copyright (c) 1989 by Academic Press, Inc All rights of reproduction in any form reserved. 
could be addressed by ESI-MS. Fenn and co-workers observed polyethylene glycol, with a nominal molecular weight of 17,500 , to have up to $23+$ charges due to multiple sodium cation attachment (12). Recently, they reported mass spectra for proteins as large as alcohol dehydrogenase (subunit, from equine liver), $M_{\mathrm{r}} \sim 40,000$, having as many as $46+$ charges per molecule (13), subsequently supported by similar results from our laboratory $(14,15)$.

The ESI phenomenon provides the basis for important new methods for the characterization of macromolecules, as well as the basis for the combination with high resolution capillary electrophoresis separation methods. We have now obtained ESI mass spectra for multiply charged proteins with molecular weights above 130,000 using a quadrupole mass spectrometer with a maximum mass-to-charge $(\mathrm{m} / z)$ limit of only 1700 . The ESI-MS method offers significant advantages due to the combination of sensitivity, extended molecular weight range with conventional mass spectrometers, and the potential for obtaining structural information on large highly charged ions (14). In addition, the series of multiply charged molecular ion peaks from ESI allows for accurate molecular weight measurements. The potential utility of these methods is further augmented by their on-line combination with high resolution capillary electrophoresis separation methods. We have previously demonstrated that both capillary zone electrophoresis (CZE) (16-18) and capillary isotachophoresis (19) can be successfully interfaced to mass spectrometry via an ESI interface. Below we describe initial studies of ESIMS and CZE-MS for polypeptides and large proteins, discuss methods for their applications, and speculate on the ultimate limitations of the technique.

\section{MATERIALS AND METHODS}

Instrumentation for ESI-MS. The ESI-MS interface for the quadrupole mass spectrometer developed at our laboratory is shown in Fig. $1(17,18)$. The ESI source consists of a $100-\mu \mathrm{m}$-i.d. fused silica capillary which protrudes $\sim 0.2 \mathrm{~mm}$ from a stainless-steel tube. A liquid sheath, typically methanol or acetonitrile, establishes electrical contact to the analyte solution eluting from the fused silica capillary (18). A voltage of between +5.0 and $+6.0 \mathrm{kV}$ (for positive ions) is applied to the stainless-steel tube, establishing the electrospray. For direct ESI-MS studies, syringe pumps controlled flow of analyte solutions and the liquid sheath at 1 and $3 \mu \mathrm{l} / \mathrm{min}$, respectively. A 3 to 6 liter/min countercurrent flow of warm $\left(80^{\circ} \mathrm{C}\right)$ nitrogen between the nozzle and the ESI source is used to aid desolvation and eliminate solvent cluster formation. The CZE-MS studies utilized electroosmotic flow in untreated fused silica capillaries; details of the methods and instrumentation are given elsewhere $(17,18)$.
Materials. All peptides and protein samples were purchased from Sigma Chemical Co., except bovine apotransferrin and creatine amidinohydrolase (Calbiochem Biochemicals), and were used without further purification. Sample solutions $(100 \mu \mathrm{M})$ were typically prepared in distilled water with glacial acetic acid added at a concentration of $1-5 \%$.

\section{RESULTS AND DISCUSSION}

\section{General Characteristics of ESI Mass Spectra for Peptides and Proteins}

In contrast with conventional mass spectrometric ionization methods negligible fragmentation of molecular ions is observed using ESI. For example, vitamin $\mathrm{B}_{12}$ (cyanocobalamine, $M_{\mathrm{r}} 1355$ ), a labile biomolecule, yields no observable fragment ions due to corrin ring fragmentation or loss of the axial cyano group, as typically observed with other desorption-ionization techniques (20). Only protonated or sodiated singly and doubly charged molecular ions are detected. Peptides such as bradykinin $\left(M_{\mathrm{r}} 1060\right)$, gramicidin $\mathrm{S}\left(M_{\mathrm{r}} 1141\right)$, gramici$\operatorname{din} \mathrm{D}\left(M_{\mathrm{r}} 1881\right)$, melittin $\left(M_{\mathrm{r}} 2845\right)$, glucagon $\left(M_{\mathrm{r}} 3480\right)$, bovine insulin $\left(M_{\mathrm{r}} 5734\right)$, and porcine insulin $\left(M_{\mathrm{r}} 5778\right)$ exhibit only multiply protonated, and in some cases multiply sodiated (depending upon solution buffer) molecular ion species by ESI $(14,15)$, with a general absence of the typical fragment ions produced with other sources $(21,22)$.

For larger molecules, a bell-shaped distribution of multiply charged molecular ions dominates the ESI mass spectrum, as first reported by Fenn and co-workers (13). The multiple charging phenomenon extends the effective molecular weight range of any mass spectrometer by a factor equal to the number of charges. For proteins (prepared in aqueous solution, $\mathrm{pH}<4$ ), an approximate linear correlation is observed between the maximum number of charges and the number of basic amino acid residues (e.g., arginine, lysine, histidine, etc.), i.e., the probable but not necessarily actual protonation sites. For example, angiotensin I $\left(M_{\mathrm{r}} 1296\right)$ contains one arginine and two histidine residues in its sequence (along with an $\mathrm{N}$-terminal amino group), consistent with the $(\mathrm{M}+4 \mathrm{H})^{4+}$ ion being the maximum charged species observed experimentally. The ( $M$ $+5 \mathrm{H})^{5+}$ and $(\mathrm{M}+6 \mathrm{H})^{6+}$ are the most abundant and most highly charged species, respectively, produced by ESI for melittin from bee venom, a peptide with 5 basic amino acids and an $\mathrm{N}$-terminal $\mathrm{NH}_{2}$ group. Similarly, horse heart cytochrome $c\left(M_{\mathrm{r}} 12,360\right)$ has 24 basic amino acids while charge states up to the $(\mathrm{M}+21 \mathrm{H})^{21+}$ species is observed. The role of other contributing moieties, such as the iron-porphyrin complex bound to the cytochrome $c$ molecule, is uncertain. Certainly other amino acid residues may be possible sites for protonation; Bojesen has 


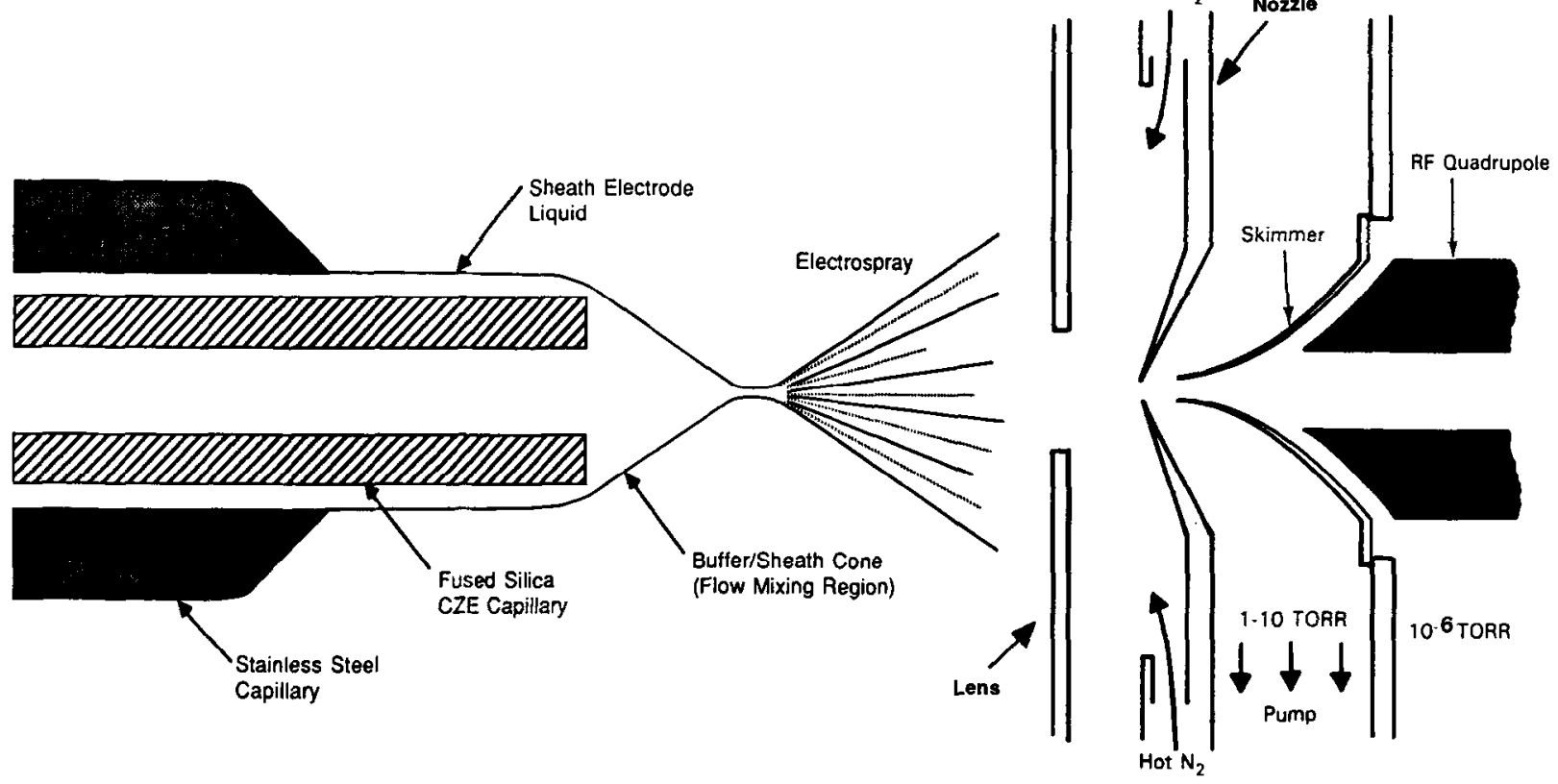

FIG. 1. Detail of the electrospray ionization interface tip and nozzle region to the quadrupole mass spectrometer (not to scale). Ions are sampled though the focusing lens and nozzle-skimmer openings to the radio frequency ( $\mathrm{r} f$ ) ion focusing quadrupole lens. Typically, $+450 \mathrm{~V}$ is applied to the focusing lens and $+200 \mathrm{~V}$ to the nozzle $\left(V_{\mathrm{n}}\right)$, while the skimmer is at ground potential. The analysis quadrupole mass spectrometer has a range of $m / z 1700$.

recently measured the relative gas-phase proton affinities of the 20 common amino acids (23).

The fact that all positive ion spectra of polypeptides and proteins with $M_{\mathrm{r}}>3,000$ studied to date (with acetonitrile or methanol sheath liquids) also yield maxima in their charge distributions below $m / z 1500$ suggests that in addition to proton affinities, the substances' surface activity, solvent composition, and electrostatic interactions may be important in determining the distribution of charge states. The Coulombic repulsion of charge sites was previously invoked to explain the ESI-MS data for various molecular weight polyethylene glycol oligomers (12). Figure 2 shows the relationship between the most abundant charge state and the molecular weight. For a protein with a globular structure, and charges evenly distributed over the surface, one would expect a maximum charge state proportional to $M_{\mathrm{r}}^{2 / 3}$. For a "spherical" 60$\mathrm{kDa}$ protein with a diameter of $\sim 6 \mathrm{~nm}$, we estimate a maximum charge state of $\leqslant 20$ based upon the Rayleigh stability limit for maintaining a spherical structure by hydrogen bonding interactions. The maximum charge state due to field emission is likely even smaller $(\leqslant 10)$. We hypothesize that these large charge states can be stabilized for gas-phase proteins only by the breaking of hydrogen bonds and loss of a higher order (secondary and tertiary) structure to an "extended" form. Such structural change would be consistent with the observed ESI separations of protein subunits (discussed later) and the nearly linear relationship between charge state and molecular weight.
Some "tailing" on the high $m / z$ side of each multiply charged molecular ion peak often occurs, as shown in the mass spectrum of sperm whale (skeletal muscle) myoglobin (Fig. 3A). Myoglobin is composed of a 153 amino acid residue chain (globin) bound to an iron-protoporphyrin IX molecule. A PD mass spectrum of myoglobin (24)

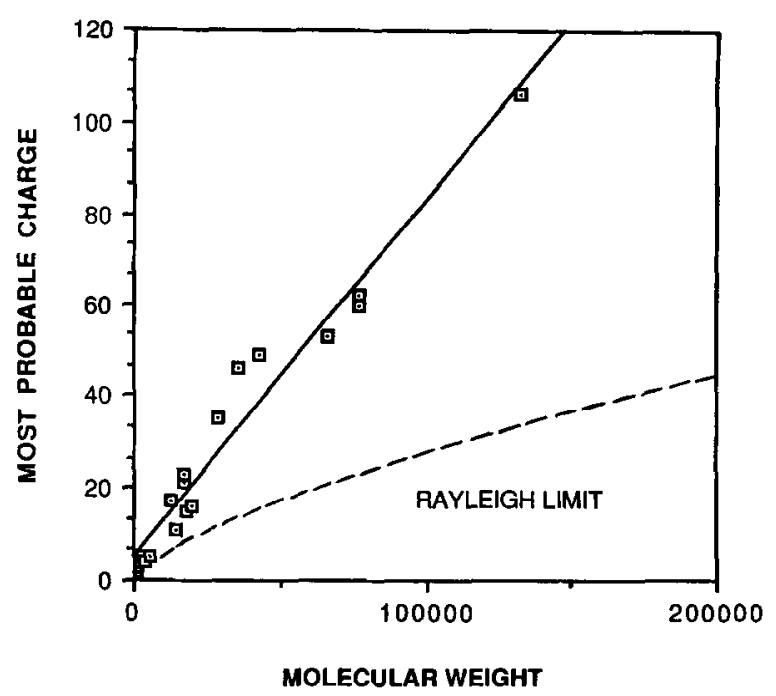

FIG. 2. Graph of most probable charge state observed by ESI-MS vs molecular weight for proteins studied to date. The Rayleigh limit is calculated for a spherical molecule having a surface tension of 7.2 $\times 10^{-2} \mathrm{~N} / \mathrm{m}$. The results suggest $a$ loss of secondary and tertiary structure to form an extended structure able to accommodate the high charge states. 


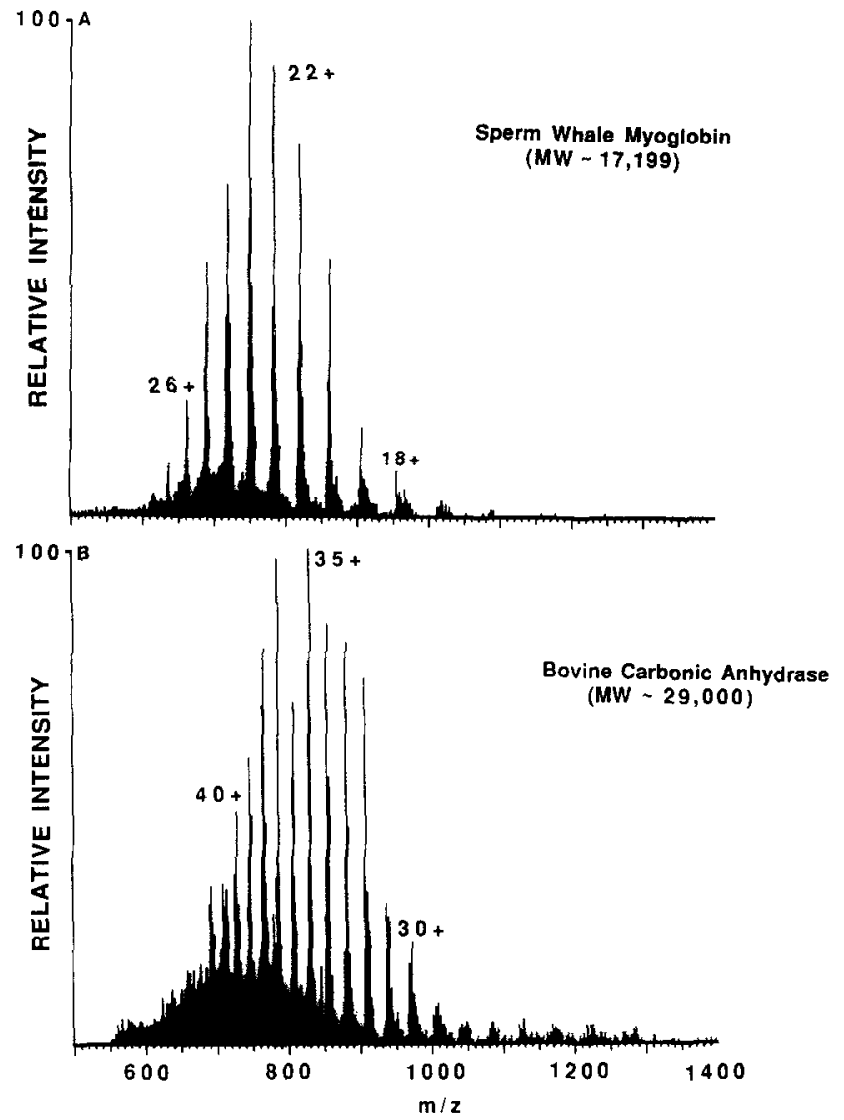

FIG. 3. ESI mass spectra of (A) sperm whale myoglobin and (B) bovine carbonic anhydrase.

shows the highest mass peaks to be due to the globin portion of the molecule. Similarly, the most intense peaks in the ESI mass spectrum of myoglobin are due to multiple charging of the globin chain $\left(M_{\mathrm{r}} \sim 17,199\right)$. Peaks of low relative abundance $(<1 \%)$ due to the intact protein molecule are also present. The tailing to higher $\mathrm{m} / \mathrm{z}$ may be due to incomplete desolvation and/or possible cation (e.g., $\mathrm{Na}^{+}, \mathrm{K}^{+}$, etc.) adduct formation, but spectra for pure substances (e.g., cytochrome $c$ in Fig. $4 \mathrm{~A})$ suggest that such contributions are minimal. Another contribution to the tailing may be the chemical heterogeneity of the protein sample.

Solvent clustering with the analyte is substantially eliminated by a countercurrent flow of nitrogen and the high nozzle potential $(\geqslant 200 \mathrm{~V})$ relative to the skimmer, which leads to collisions in the nozzle-skimmer region that effectively detach weakly bound solvent molecules. As an example, with the nozzle at $+235 \mathrm{~V}$, over $40+$ charges are clearly resolved in the ESI mass spectrum of bovine carbonic anhydrase $\left(M_{\mathrm{r}} \sim 29,022\right)$, shown in Fig. $3 \mathrm{~B}$. Decreasing the potential to $+100 \mathrm{~V}$ yields peaks that are significantly broader and less intense while the total ion current remains nearly constant; such changes can be attributed to incomplete desolvation of molecular ions.
Significantly higher nozzle voltages than required for desolvation lead to lower ion abundances due to collision-induced dissociation (CID) of the large multiply charged molecular ions in the nozzle-skimmer region of our instrument (14). CID processes are more efficient as the parent size or $m / z$ decreases $(14,25,26)$. More highly charged species (at lower $m / z$ values) from ESI are readily dissociated, as demonstrated by their disappearance upon increasing the nozzle potential. For example, mass spectra of bovine hemoglobin $\left(M_{\mathrm{r}} \sim 65,000\right)$ with $V_{\mathrm{n}}=+200 \mathrm{~V}$ are dominated by multiply charged ions (up to $25+)$ due to the two $\alpha$ chains $\left(M_{\mathrm{r}} \sim 15,050\right)$ and the two $\beta$ polypeptide chains $\left(M_{\mathrm{r}} \sim 15,970\right)$ along with a peak due to the iron-heme unit. At $V_{\mathrm{n}}=+300 \mathrm{~V}$, ions with charges $21+$ to $25+$ disappear. In Figure $4 \mathrm{~A}$, a typical electrospray ionization mass spectrum is shown for horse heart cytochrome $c\left(V_{\mathrm{n}}=+200 \mathrm{~V}\right)$. Raising the nozzle potential above $+400 \mathrm{~V}$ results in a substantial loss of the more highly charged species along with the appearance of a peak due to the iron-porphyrin complex $(m / z 617)$ associated with the protein (Fig. 4B). Preliminary tandem mass spectrometry (i.e., MS-MS) results

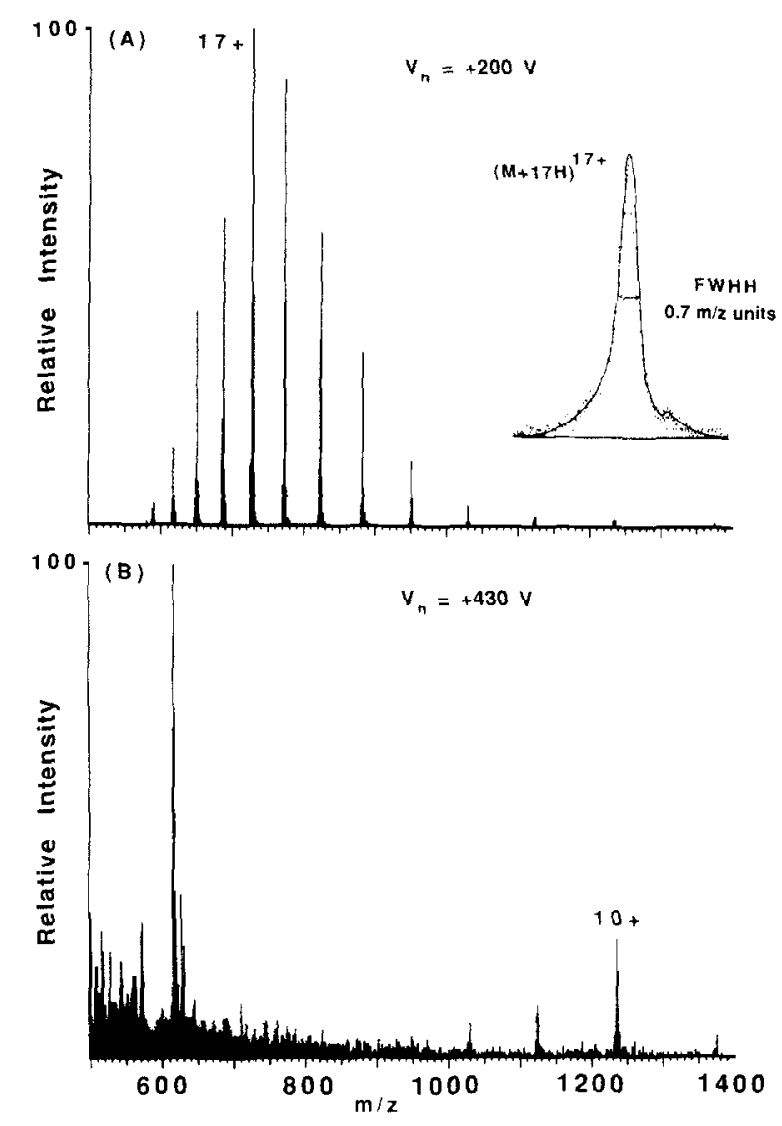

FIG. 4. ESI mass spectra obtained from $30 \mathrm{pmol}$ of horse heart cytochrome $c$ with the nozzle voltage at $(\mathrm{A})+200 \mathrm{~V}$ and $(\mathrm{B})+430 \mathrm{~V}$. The inset shows an expansion of the $17+$ peak; the peak profile is defined by the isotopic distribution and the resolution of the mass spectrometer and shows no significant solvent association. 
from a triple quadrupole MS with ESI for cytochrome $c$ has also yielded the $m / z 617$ ion under high collision energy conditions (27). For smaller peptides, singly and multiply charged sequence ions can be readily identified in ESI mass spectra obtained with higher $(>+200 \mathrm{~V})$ nozzle potentials. This possibility of CID of preselected large multiply charged molecules by tandem mass spectrometry, not obtained for large molecules in low charge states $(25,28)$, suggests that direct structural studies (e.g., sequencing) of large molecules may at last be practical using sequential fragmentation steps (i.e., $\mathrm{MS}^{n}, n$ $\geqslant 2$ ). Recent results support this suggestion (27).

\section{Molecular Weight Determination}

A feature of ESI mass spectra for macromolecules is that accurate molecular weight measurements can be readily obtained. The ultimate accuracy of molecular weight measurements is defined by the instrumental parameters (resolution, $m / z$ measurement accuracy, etc.) and any uncontrolled adduction of solvent molecules or ions (e.g., a sodium cation instead of a proton) which causes the mass of the ion to differ from the expected molecular species. For high molecular weight substances $(>2000)$, the low resolution of a quadrupole mass spectrometer does not allow resolution of each isotopic contribution to the molecular ion, and methods involving molecular weight determination from the most abundant ion or the average mass (based upon the centroid of the molecular ion envelope) must be used $(29,30)$. Although the multiple charging process produces a mass spectrum of unconventional appearance, it is straightforward to determine the charge state of each ion and the molecular weight since adjacent peaks differ by only one charge. For a pure compound three peaks serve to define the series and, any two peaks provide sufficient information to determine both the number of charges and the ion mass. Each additional molecular ion peak provides an independent measurement of the compound's molecular weight and improved precision (13).

Equation [1] describes the relationship between a multiply protonated ion at $m / z p_{1}$ with charge $z_{1}$ and the average molecular weight:

$$
p_{1} z_{1}=\text { molecular weight }+1.0079 z_{1} .
$$

The molecular weight of a second multiply protonated ion at $m / z p_{2}$ (where $p_{2}>p_{1}$ ) that is $j$ peaks away from $p_{1}$ (e.g., $j=1$ for two adjacent peaks) is given by

$$
p_{2}\left(z_{1}-j\right)=\text { molecular weight }+1.0079\left(z_{1}-j\right) .
$$

Equations [1] and [2] can be solved for the charge of $p_{1}$ :

$$
z_{1}=j\left(p_{2}-1.0079\right) /\left(p_{2}-p_{1}\right)
$$

$z_{1}$ is taken as the nearest integer value allowing the
TABLE 1

Molecular Weight Determination of Small Proteins (up to 30,000 ) by ESI-MS

\begin{tabular}{lrr}
\hline \multicolumn{1}{c}{ Molecule } & $\begin{array}{c}\text { Average } M_{r} \\
\text { determined }\end{array}$ & $\begin{array}{c}\text { Calculated } \\
\text { Average } \\
M_{\mathrm{r}}\end{array}$ \\
\hline $\begin{array}{l}\text { Insulin (bovine pancreas) } \\
\text { Cytochrome } c \text { (horse heart) }\end{array}$ & $\begin{array}{c}12,733.9 \pm 0.5 \\
\text { Lysozyme (hen egg) }\end{array}$ & $5,733.6$ \\
$\begin{array}{l}\text { Lysozyme (human milk) } \\
\text { Myoglobin }\end{array}$ & $14,304.6 \pm 4.7$ & $12,360.1$ \\
Myoglobin ${ }^{b}$ (sperse heart) & $14,695.2 \pm 4.4$ & $14,306.2$ \\
$\quad$ skeletal muscle) & $16,949.0 \pm 4.4$ & $14,692.8$ \\
$\begin{array}{l}\text { Trypsin inhibitor (soybean) } \\
\text { Carbonic anhydrase (bovine }\end{array}$ & $17,197.0 \pm 5.5$ & $17,1950.7$ \\
$\quad$ erythrocytes) & $20,097.6 \pm 15.8$ & $20,090.9$ \\
\hline
\end{tabular}

\footnotetext{
${ }^{a}$ From sequence data, Ref. (31).

${ }^{b}$ Protein portion.

${ }^{c}$ From Sigma Chemical.
}

charge of each ion in the multiple charge distribution and the molecular weight to be obtained.

Table 1 lists average molecular weight measurements for several proteins by ESI-MS. Although no special care was taken in mass spectrometer calibration, and the computer controlled data system limited measurements to $\pm 0.2 \mathrm{~m} / z$ precision at $\mathrm{m} / \mathrm{z} 1000$, agreement with values from sequence information (31) was obtained with accuracies generally better than $\pm 0.05 \%$. Since our mass spectral data system records peak abundances at integer mass values, the precision can be further increased with improvements in software that allow exact mass determination and centroid analysis. Improved precision of $\pm 0.008 \%$ for bovine insulin (Table 1) was obtained by measuring the exact peak positions from an oscilloscopic recording. For larger proteins, even though the purity of most materials was doubtful, molecular weight was determined with a precision of better than $\pm 0.05 \%$ for the dominant component (see following section). As an example, the average molecular weight for bovine albumin was determined to be $66,598 \pm 19$ in close agreement with other methods (32).

The present results suggest that protein molecular weight should be routinely obtainable to better than $0.01 \%$ with improvements in calibration and data acquisition software. Consideration of the precision and accuracy of measurements reported obtainable using quadrupole mass spectrometers suggests that mass accuracies of $\pm 0.0006 \%$ are feasible (33). Accuracies on the order of $1 \mathrm{ppm}(0.0001 \%)$ should be obtainable by combination of ESI with conventional double focusing mass spectrometers or Fourier transform mass spectrometers.

This approach offers significant advantages over previous mass spectrometric methods for molecular weight measurements. While on the order of $1 \mathrm{pmol}$ of sample 


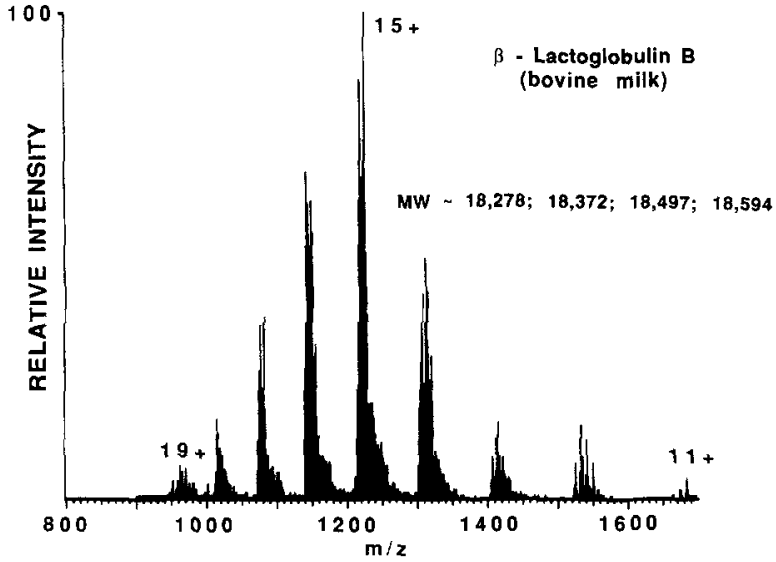

FIG. 5. ESI mass spectrum of a $\beta$-lactoglobulin B (bovine milk) sample showing evidence for a minimum of four components.

is required at present, substantial improvements in sensitivity appear possible. Since complete spectra can be acquired in only a few seconds, molecular weight determination by ESI-MS is much faster than PD-MS. The precision and accuracy of ESI-MS measurements are at least an order of magnitude better than PD-MS $(3,30)$ and laser desorption-MS $(7,8)$, which are based upon time-of-flight mass spectrometers. Compared to the most commonly employed technique, sodium dodecyl sulfate-polyacrylamide gel electrophoresis, measurement times are considerably faster with at least two orders of magnitude better accuracy.

\section{ESI Mass Spectra of Proteins and Ultimate Molecular Weight Limitations}

As shown in Fig. 4A for cytochrome c, pure protein samples yield high quality spectra with peak widths governed by the isotopic distribution and the resolution of the mass spectrometer. Many commercially obtained proteins studied to date have shown evidence of heterogeneity and other contributions that result in more complex spectra. Proteins consisting of noncovalently bound subunits yield ions indicative of the subunit molecular weight, such as described above for hemoglobin. For example, $\beta$-lactoglobulin is a protein of approximate $M_{\mathrm{r}}$ 36,000 and composed of two subunits. The ESI-MS spectrum of $\beta$-lactoglobulin B (bovine milk) shown in Fig. 5 indicates a mixture with at least four species having $M_{\mathrm{r}}$ values of approximately $18,278,18,372,18,496$, and 18,594. Lactate dehydrogenase from rabbit muscle is an isozyme made up of four subunits, each of $M_{\mathrm{r}}$ approximately 35,000 . The molecular weight of the subunit obtained from its mass spectrum (Fig. $6 \mathrm{~A}$ ) is $\sim 35,700$. Similarly, a spectrum of creatine amidinohydrolase (Pseudomonas sp.) shows an approximate $M_{\mathrm{r}} 30,700$, whereas the reported average molecular weight (Calbiochem Biochemicals) is 94,000 . Also, creatine phosphoki- nase from rabbit muscle (a dimeric enzyme of $82 \mathrm{kDa}$ ) shows multiply charged ions from separate $42,160-\mathrm{Da}$ species. We postulate that the production of high charge states during ESI and the removal of the stabilizing effects of the solvent (with the loss of secondary and ternary structure) result in the mutual repulsion (separation) of protein subunits. This loss of quaternary structure is consistent with the loss of secondary and tertiary structure postulated earlier.

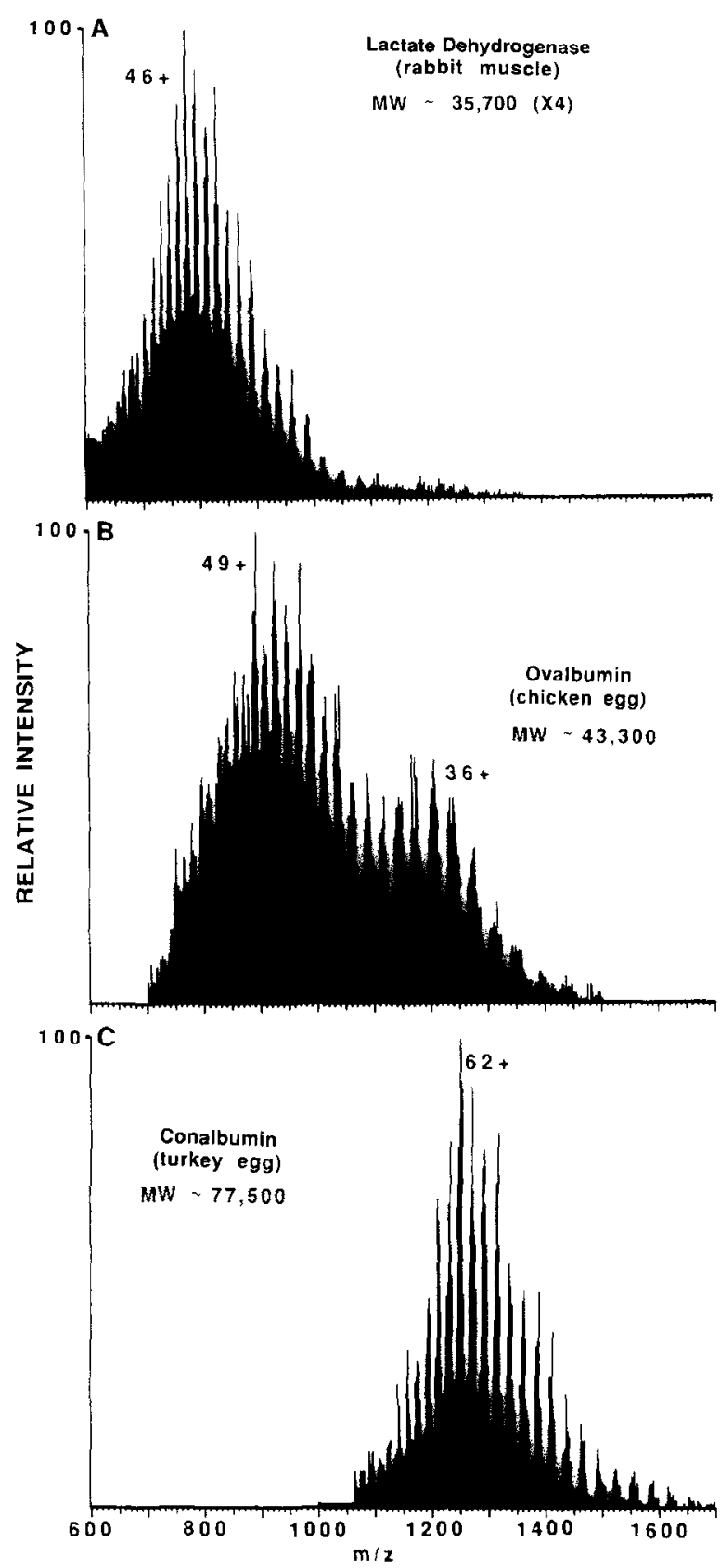

FIG. 6. ESI mass spectra of (A) lactate dehydrogenase from rabbit muscle, (B) chicken egg albumin (ovalbumin), and (C) conalbumin from turkey egg white. 


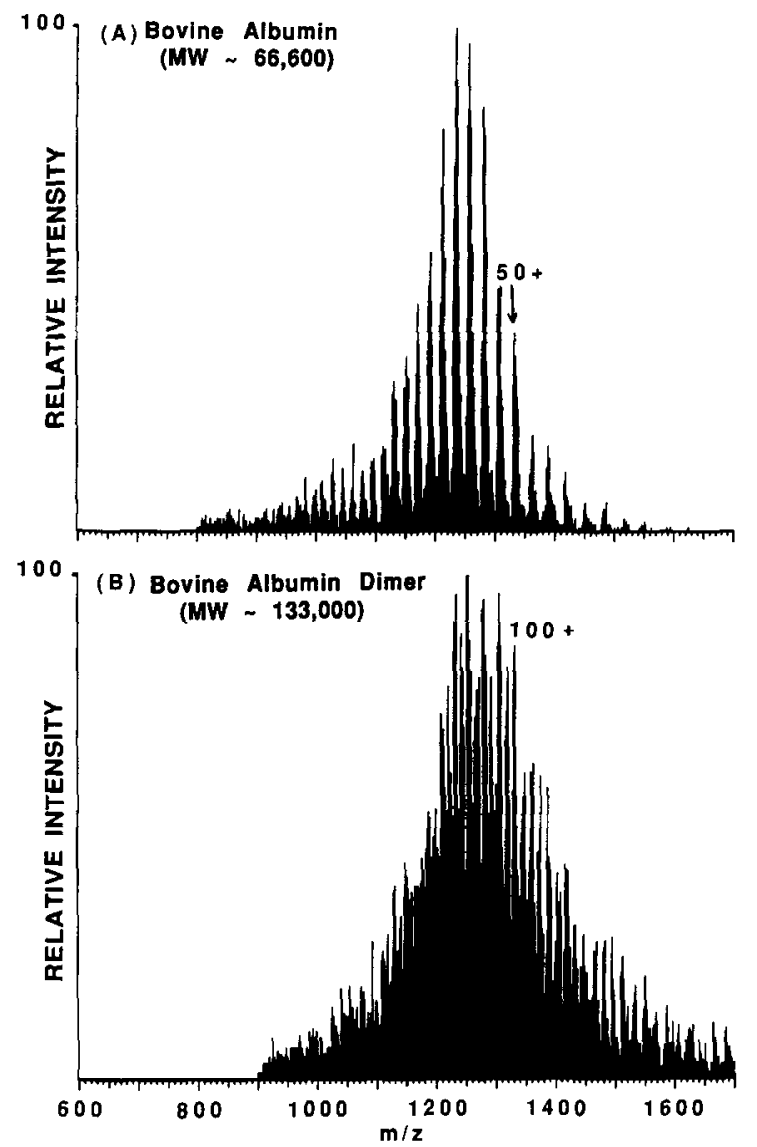

FIG. 7. ESI mass spectra of (A) bovine albumin and (B) bovine albumin dimer.

ESI-MS results were readily obtained from higher molecular weight proteins; for example, intact molecular ions were obtained in good yield for ovalbumin from chicken egg $\left(M_{\mathrm{r}} \sim 43,300\right)$ (Fig. 6B), bovine albumin $\left(M_{\mathrm{r}} \sim 66,600\right)$ (Fig. 7A), bovine apotransferrin $\left(M_{\mathrm{r}}\right.$ $\sim 77,013)$, and turkey egg conalbumin $\left(M_{\mathrm{r}} \sim 77,500\right)$, (Fig. 6C). A sample of human albumin yielded similar mass spectra to its bovine counterpart, indicating very similar molecular weights. The spectrum for apotransferrin shows a series of doublets that indicates the presence of another species with a molecular weight of 76,736 \pm 30 . Bovine transferrin is known to be heterogeneous with two bands observed in electrophoresis (34). A sample of conalbumin from chicken egg (ovotransferrin) yielded a mass spectrum identical to the turkey egg sample, both indicating multiple charging up to the $73+$ ion. The spectrum for the largest protein yet studied by ESIMS is shown in Fig. 7B, a bovine albumin "native" dimer $\left(M_{\mathrm{r}} \sim 133,000\right)$. The highest charged species clearly resolved is the $120+$ multiply protonated albumin dimer. The large width of the molecular ion envelopes suggests either that such large molecules can retain solvent in substantial quantity (unlike smaller proteins) or that substantial heterogeneity exists, which we consider most likely. Future studies with both higher purity materials and MS-MS studies across the ion envelope should resolve this point.

One can speculate on the ultimate molecular weight limitations of the ESI-MS method. Each charge state has a minimum peak width determined by the ${ }^{13} \mathrm{C}$ and other isotopic contributions (29). Peak widths for multiply charged proteins actually decrease with increasing molecular weight because the increased isotopic envelope width (at half height) is less than the increase in charge state necessary for a constant $\mathrm{m} / z$. The peak width, among other factors, defines how closely adjacent charge states can be located and still be resolved. For example, the polystyrene oligomer $\left(\mathrm{C}_{4} \mathrm{H}_{9}\left(\mathrm{C}_{8} \mathrm{H}_{8}\right)_{n} \mathrm{H}\right)$ at $n$ $=100$ (average $M_{\mathrm{r}} \sim 10,470$ ), has a calculated full width at half the peak height (FWHH) for the 10+ multiply protonated ion of $\sim 0.7 \mathrm{~m} / z$ units (29). For polystyrene of $n=1000$, FWHH for the $100+$ ion is approximately $0.22 \mathrm{~m} / z$ units. Molecular weight limitations will certainly depend on instrument resolution, signal-to-noise, and compound purity and (when ions are formed in the $\mathrm{m} / \mathrm{z} 1000$ range) can be estimated to be on the order of a few million daltons due to insufficient peak resolution. While the capability to produce molecular ions in the million dalton range has not been demonstrated, other limitations may exist due to sensitivity (which drops linearly with molecular weight due to the increased number of charge states through which the signal is dispersed) and even, perhaps, the physical dimensions of the ion ( $\mu \mathrm{m}$ range for MDa molecules).

\section{Capillary Electrophoresis-Mass Spectrometry}

The combination of capillary electrophoresis (35) with on-line mass spectrometric detection via the ESI interface couples a potentially fast high resolution separation method with the potentially ideal detector (1618). Capillary electrophoresis has the ability to handle very small volume samples (picoliter range) and attomole $\left(10^{-18} \mathrm{~mol}\right)$ level detection limits with separation efficiencies on the order of $10^{6}$ theoretical plates $(17,35)$. With the coupling of a micropipet to a CZE capillary, cytoplasmic material from single snail nerve cells has been analyzed (36). Previous attempts at CZE of small proteins (with uv detection) (35) have often resulted in broad, tailing peaks due to adsorption of proteins on active sites of the negatively charged capillary wall. However, separations performed in buffered systems with the $\mathrm{pH}$ above the protein isoelectric point $(\mathrm{p} I)$ allow both the proteins and the capillary wall to be negatively charged and mutually repulsive and can greatly improve resolution (37). Initial studies of positive ion ESI-MS of peptides and proteins in buffer solutions above their $\mathrm{p} I$ resulted in over an order of magnitude loss in sensitivity relative to more acidic conditions, reflecting lower efficiencies for analyte protonation. However, by using a 

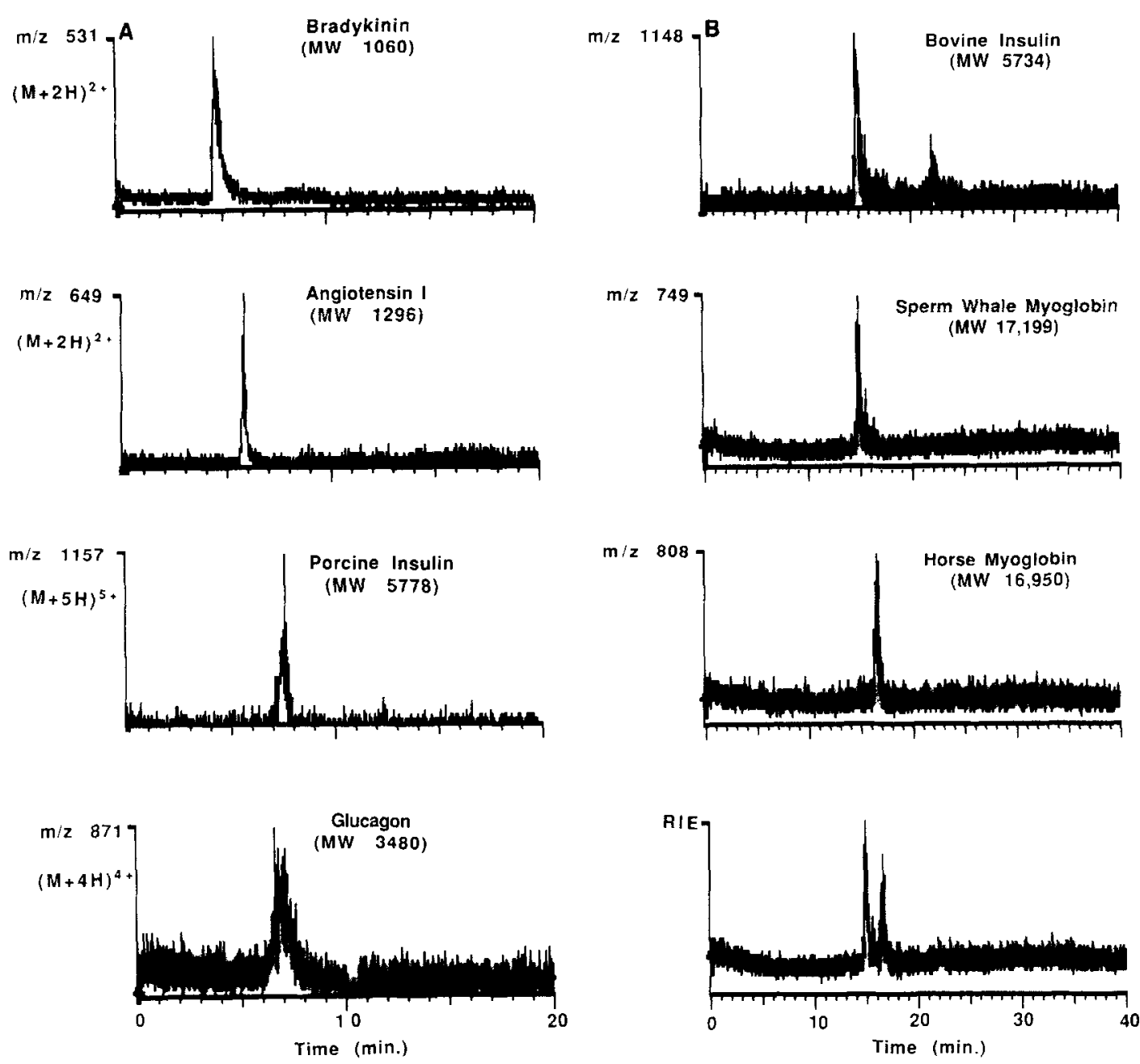

FIG. 8. (A) Single ion electropherograms for separation of peptide mixture by CZE-MS consisting of approximately 5 pmol/component separated with use of $0.6 \mathrm{~m} \times 100 \mu \mathrm{m}$ i.d. fused silica capillary at $15 \mathrm{kV}$; (B) single ion electropherograms and a reconstructed ion electropherogram (RIE) for a peptide and protein mixture. Approximately 2 pmol/component in a $\mathrm{pH} 8.4$ buffered system was electrokinetically injected. An untreated $1.1 \mathrm{~m} \times 100 \mu \mathrm{m}$ i.d. capillary was used for the separations at $25 \mathrm{kV}$.

liquid sheath consisting of 80:10:10 methanol:water:glacial acetic acid, initial attempts at CZE-MS of peptides in a pH 11 sodium phosphate buffer (Fig. $8 \mathrm{~A}$ ) show that bradykinin, angiotensin $I$, and porcine insulin were resolved. Improved separations are still required, as evident by the excessive tailing for the glucagon peak. For larger proteins with $\mathrm{p} I<11$, denaturation occurs under the high $\mathrm{pH}$ conditions (37). With a $\mathrm{pH} 8.4$ Tris/HCl buffer, 2 pmol of bovine insulin, sperm whale myoglobin (skeletal muscle), and equine myoglobin (heart) were successfully separated by CZE-MS (Fig. 8B). Bovine insulin elutes at $22 \mathrm{~min}$ and is well separated from the myoglobins. While improved sensitivity and resolution is obviously desired, these initial CZE-MS results represent the first on-line electrophoretic (or chromatographic) separation and mass spectrometric detection of proteins. Recent developments allowing high resolution CZE separations of proteins in low $\mathrm{pH}$ buffers using spe- cially modified capillaries (38) should offer a basis for improved separations and sensitivity. The related technique of capillary isotachophoresis-MS also provides an attractive combination due to its ability to handle larger sample volumes with low analyte concentrations, allowing concentration of trace analyte bands (19).

\section{CONCLUSIONS}

The combination of high-performance capillary electrophoresis methods for separation of femtomole quantities with analysis by ESI-MS and MS-MS offers a powerful new method for biochemical research. Proteins with molecular weights in excess of 130,000 have been successfully analyzed by mass spectrometry based upon electrospray ionization, which produces multiply charged molecular ions allowing accurate molecular weight measurements of proteins with precisions and ac- 
curacies easily less than $\pm 0.05 \%$ using a quadrupole instrument of limited $m / z$ range. Similar results for biomolecules with molecular weights greater than 200,000 (and perhaps as great as $10^{6}$ ) should be feasible. The ultimate molecular weight limitations of the technique may be an order of magnitude greater mass. Consideration of instrumental limitations for quadrupole mass spectrometers suggests molecular weight accuracies at least an order of magnitude better are obtainable. Such rapid molecular weight measurements have broad potential application due to the sensitivity of the method and the ability to resolve changes in a single amino acid residue, subtle protein modifications, and the evaluation of protein purity.

The lack of fragmentation by ESI-MS places premier importance on obtaining additional structural information using tandem mass spectrometry $(25,27,28)$. The efficient dissociation of large multiply charged ions generated by electrospray ionization offers exciting opportunities, which may even include direct protein sequencing through the use of multidimensional mass spectrometry $\left(\mathbf{M S}^{n}\right)$. Such applications will depend on the information content of MS-MS spectra for large molecules and further study is required to access the feasibility of such an approach. Preliminary results show substantial structural intermation may be obtainable in such studies (39).

\section{ACKNOWLEDGMENTS}

The authors thank C. J. Barinaga, C. G. Edmonds, and H. K. Jones for helpful discussions. This work was supported by the U.S. Department of Energy, Office of Health and Environmental Sciences, under Contract DE-AC06-76RLO 1830 and PNL Exploratory Research.

\section{REFERENCES}

1. Barber, M., Bordoli, R. S., Elliott, G. J., Sedgwick, R. D., and Tyler, A. N. (1982) Anal. Chem. 54, 645A-657A.

2. Sundqvist, B., and Macfarlane, R. D. (1985) Mass Spectrom. Rev. 4, 421-460.

3. Roepstorff, P., and Sundqvist, B. (1986) in Mass Spectrometry in Biomedical Research (Gaskell, S. J., Ed.), pp. 269-285, Wiley, London.

4. Craig, A. G., Engstrom, ̊., Bennich, H., and Kamensky, I. (1987) in Proceedings of the 35th Annual Conference on Mass Spectrometry and Allied Topics, pp. 528-529, Denver, CO.

5. Cotter, R. J. (1988) Anal. Chem. 60, 781A-793A.

6. Barber, M., and Green, B. N. (1987) Rapid Commun. Mass Spectrom. 1, 80-83.

7. Karas, M., and Hillenkamp, F. (1988) Anal. Chem. 60, $2299-2301$.

8. Karas, M., and Hillenkamp, F. (1988) Paper presented at the 11th International Mass Spectrometry Conference, Bordeaux, France.

9. Dole, M., Mack, L. L., Hines, R. L., Mobley, R. C., Ferguson, L. D., and Alice, M. B. (1968) J. Chem. Phys. 49, 2240-2249.
10. Yamashita, M., and Fenn, J. B. (1984) J. Phys. Chem. 88, 44514459.

11. Whitehouse, C. M., Dreyer, R. N., Yamashita, M., and Fenn, J. B. (1985) Anal. Chem. 57, 675-677.

12. Wong, S. F., Meng, C. K., and Fenn, J. B. (1988) J. Phys. Chem. 92, 546-550.

13. Meng, C. K., Mann, M., and Fenn, J. B. (1988) Z. Phys. C. Atoms Molecules Clusters 10, 361-368.

14. Loo, J. A., Udseth, H. R., and Smith, R. D. (1988) Rapid Commun. Mass Spectrom. 2, 207-210.

15. Loo, J. A., Udseth, H. R., and Smith, R. D. (1988) Biomed. Environ. Mass Spectrom. 17, 411-414.

16. Olivares, J. A., Nguyen, N. T., Yonker, C. R., and Smith, R. D. (1987) Anal. Chem. 59, 1230-1232.

17. Smith, R. D., Olivares, J. A., Nguyen, N. T., and Udseth, H. R. (1988) Anal. Chem. 60, 436-441.

18. Smith, R. D., Barinaga, C. J., and Udseth, H. R. (1988) Anal. Chem. 60, 1948-1952.

19. Udseth, H. R., Loo, J. A., and Smith, R. D. Anal. Chem., in press.

20. Schiebel, H. M., and Schulten, H.-R. (1986) Mass Spectrom. Rev. 5, 249-311.

21. Amster, I. J., Loo, J. A., Furlong, J. J. P., and McLafferty, F. W. (1987) Anal. Chem. 59, 313-317.

22. Biemann, K., and Martin, S. A. (1987) Mass Spectrom. Rev. 6, 1 76.

23. Bojesen, G. (1987) J. Amer. Chem. Soc. 109, 5557-5558.

24. Grace, L. I., Chait, B. T., and Field, F. H. (1987) Biomed. Environ. Mass Spectrom. 14, 295-299.

25. McLafferty, F. W. (Ed.) (1983) Tandem Mass Spectrometry, Wiley, New York.

26. Neumann, G. M., Sheil, M. M., and Derrick, P. J. (1984) Z. Naturforsch. 39a, 584-592.

27. Barinaga, C. J., Udseth, H. R., and Smith, R. D. (1989) Rapid Comm. Mass Spectrom., in press.

28. McLafferty, F. W. (1986) in Mass Spectrometry in the Analysis of Large Molecules (McNeal, C. J., Ed.), pp. 107-120, Wiley, Chichester.

29. Yergey, J., Heller, D., Hansen, G., Cotter, R. J., and Fenselau, C. (1983) Anal. Chem. 55, 353-356.

30. Roepstorff, P., Højrup, P., Sundqvist, B. U. R., Jonsson, G., Håkansson, P., Andersen, S. O., and Johansson, K. E. (1986) Biomed. Environ. Mass Spectrom. 13, 689-691.

31. Croft, L. R. (1973) Handbook of Protein Sequences, JoynsonBruvvers Ltd., Oxford, UK.

32. Peters, 'T., Jr. (1985) in Advances in Protein Chemistry (Anfinsen, C. B., Edsall, J. T., and Richards, F. M., Eds.), Vol. 37, pp. 161245, Academic Press, Orlando, FL.

33. Roboz, J., Holland, J. F., McDowall, M. A., and Hillmer, M. J. (1988) Rapid Commun. Mass Spectrom. 2, 64-66.

34. Brock, J. H. (1985) in Metalloproteins, Part 2: Metal Proteins with Non-redox Roles (Harrison, P. M. Ed.), Vol. 7, pp. 183-262, Verlag Chemie, Weinheim.

35. Jorgenson, J. W., and Lukacs, K. D. (1983) Science 222, 266-272.

36. Wallingford, R. A., and Ewing, A. G. (1988) Anal. Chem. 60, $1972-1975$.

37. Lauer, H. H., and McManigill, D. (1986) Anal. Chem. 58, 166170.

38. McCormick, R. M. (1988) Anal. Chem. 60, 2322-2328.

39. Smith, R. D., and Barinaga, C. J., J. Amer. Chem. Soc., submitted. 